\title{
Focusing on Men and Fathers: A Challenge for Social Work Research and Practice
}

\author{
Kevin Shafer \\ Brigham Young University - Provo, kshafer@byu.edu \\ Jennifer L. Bellamy \\ University of Denver
}

Follow this and additional works at: https://scholarsarchive.byu.edu/facpub

Part of the Family, Life Course, and Society Commons, and the Gender and Sexuality Commons

\section{Original Publication Citation}

Shafer, K. \& Bellamy, J.L. (2016). "Guest Editorial: Focusing on Men and Fathers-A Challenge for Social Work Research and Practice." Social Work Research, 40(4): 199-202.

\section{BYU ScholarsArchive Citation}

Shafer, Kevin and Bellamy, Jennifer L., "Focusing on Men and Fathers: A Challenge for Social Work Research and Practice" (2016). Faculty Publications. 4382.

https://scholarsarchive.byu.edu/facpub/4382

This Other is brought to you for free and open access by BYU ScholarsArchive. It has been accepted for inclusion in Faculty Publications by an authorized administrator of BYU ScholarsArchive. For more information, please contact ellen_amatangelo@byu.edu. 


\title{
Focusing on Men and Fathers: A Challenge for Social Work Research and Practice
}

\author{
Kevin Shafer and Jennifer L. Bellamy
}

I $\mathrm{n}$ introducing this special issue of Social Work Research, we feel it is important to discuss why social work practice and research with men and fathers is of critical importance and deserving of specific attention. Social work researchers and practitioners need to focus on men and fathers, both as a special population and as subpopulations of other groups. A focus on men and fathers is critical because (a) it is a social justice issue for men, women, and children; (b) men are underserved by helping professionals, including social workers, particularly in certain contexts and programs; (c) social workers are uniquely positioned to tackle the most pressing problems men face; and (d) social work values suggest that addressing men's issues is necessary to our identity as social workers.

Compared with women and children, men occupy a privileged position within society. Yet, marginalization and oppression are shouldered by many men, including, but not limited to, men of color, the incarcerated, and men who are sexual minorities. Furthermore, the intersections between these identities, experiences, and male gender have unique implications for social work practice. More broadly, numerous challenges affect the worth, well-being, and dignity of many men. Examples of the issues include high rates of suicide; early mortality and morbidity; and significant mental health issues such as depression, anxiety, and posttraumatic stress disorder (Furman, 2013). The articles in this special issue highlight some of these particular risks and challenges.

It is perhaps more problematic that men are not optimally engaged in various areas of social work, including mental health, child welfare, and early childhood intervention. More than $80 \%$ of social workers are women (U.S. Department of Labor, Bureau of Labor Statistics, 2016), and many female social workers feel uncertainty or even resistance toward working with men, particularly in services and spaces that have traditionally been reserved for women. In the same vein, social work research has failed to address the various problems and issues that many men face and how these concerns affect individuals, women, children, families, and communities. As we understand men in the context rather than in isolation, the failure to recognize and serve men in their various roles is a disservice to the communities and families of which they are a part. In our experience, the roles and needs of men are often considered through more punitive services and systems designed to address deficits and risks such as criminal justice, child support, or substance abuse treatment, and less often in prevention, education, and child and family services.

A failure to well attend the problems and concerns of half the population is serious and even dangerous. Just like women, men suffer a greater risk of certain diseases and poorer outcomes due to their gender. Men die by suicide four times more often than women (National Institute of Mental Health, 2005), which may be exacerbated, in part, by the fact that more than half of men with mental health issues receive neither formal nor informal treatment (Addis \& Mahalik, 2003). Drug and alcohol abuse rates among men are significantly greater than among women (World Health Organization, 2007). Men are, far and away, the most common perpetrators of violence against women, children, and other men (Jewkes, Flood, \& Lang, 2015). Men also engage in a greater number of unhealthy behaviors, like smoking, eating a poor diet, and practicing risky behaviors than women (Oksuzyan, Juel, Vaupel, \& Christensen, 2008). Solutions to these issues should be sought, particularly because men significantly (either positively or negatively) influence the world around them. As just one example, research clearly and consistently illustrates that engaged and involved fathers have a 
positive, long-lasting impact on the physical, mental, social, and cognitive well-being of their children (Coley \& Coltrane, 2007). Perhaps this is one reason why men have become more involved in the lives of their children than ever before. And yet, as is typical when talking about men's issues, this trend is countervailed by the fact that there are more absentee fathers today than ever before (Holmes, Baumgartner, Marks, Palkovitz, \& Nesteruk, 2010).

Despite the privileged position of male gender, our concern with men and fathers is deeply rooted in social justice. Several examples stand out. The Black Lives Matter movement has emphasized the problems, challenges, and marginalization of the African American community, which often disproportionately affect black men. Movements focusing on the concerns of undocumented immigrants often emphasize the separation and extended isolation of men and boys from their families. The recent dialogue about criminal justice reform has increased attention on an issue that unduly affects men of color. Moreover, many mentally ill people, particularly poor men and men of color, only receive treatment through the criminal justice system.

Each of these issues, on their own, affects families in a myriad of ways, and looking at them with a specific focus on the needs of men is necessary. Social work's focus on social justice demands that we recognize and help fathers take on positive family roles. Many men can, and do, play strong and supportive roles in their families and in their communities. Making more explicit, consistent, and strong supports for positive male roles in families and communities would move social services away from a female-centric (and female-burdening) model and support greater gender egalitarianism across a myriad of roles and expectations. If, for example, social workers provide fathers with the necessary and appropriate tools to become increasingly engaged in their families, there may be a more even distribution of parental expectations and family burdens. A change in these expectations and burdens would benefit both men and women by affecting overly restrictive gender boundaries that have unfairly encumbered men and placed constrictive boundaries on women. Providing men with equal access to supports, such as access to family, mental health, and other social services designed to help them with parenting outside of a pure breadwinning role may help reduce the discrimination women experience as a result of unfair expectations related to motherhood.
It is also problematic that men often eschew the few community services that are open to their inclusion. Numerous studies have addressed the strong barriers, such as masculine norms, which typically prevent men from accessing services from social workers and other helping professionals. These barriers are deeply ingrained into mainstream U.S. culture and reflected in the service systems, policies, and programs in the United States. Self-reliance, problem avoidance, strength, bravery, and emotionlessness are viewed as positive masculine traits (Addis, 2008; Courtenay, 2011). It is not surprising, then, that many men report that seeking help through clinical or community services is incompatible with their identity. Other men lack confidence in the mental health and supportive services provided by social workers and other helping professionals, sometimes due to prior negative service experiences. Still others fail to recognize that they need help or do not realize that they are eligible to access services (Rochlen et al., 2010).

Several examples from the research literature suggest that men's suspicion of mental health, social, and supportive services is not without cause, however. Afifi (2007) argued that gendered notions of mental health may cloud clinical judgment by finding that women are far more likely to be diagnosed with depression, even when they score the same as men on diagnostic instruments. Bellamy (2009) noted that, in many cases, child welfare workers subscribe to negative concepts of men and fathersoften labeling them as "dangerous," "absent," and "unimportant." Baum (2016) noted that virtually no research has addressed men's experiences with life transitions, stressful events, emotions, or stress, and that social work education fails to address concerns that are unique to or that disproportionately affect men. Thus, it appears that many areas of social work practice experience substantial gender imbalance, neglecting the problems and issues of men. It is perhaps unsurprising, then, that Rochlen and colleagues (2010) indicated that men often feel misunderstood or unwanted by helping professionals, including social workers.

Research on issues related to men, particularly in the realm of mental health, suicide, and service engagement, has been ceded primarily to psychology and public health, even though social work is uniquely positioned to address the needs and concerns of men. First, it should be clear that social 
workers serve far too many men through the criminal justice and child support systems and far too few through family resource centers, home visiting, community services, and mental health clinics. It is troubling that low-income men, men of color, and men marginalized by mental health issues, criminal justice involvement, and other problems often have limited access to supportive rather than punitive or restrictive economic-focused systems, like workforce development. Second, social workers are the "ground soldiers" of the helping professionals. Instead of having clients come to our office in the style of The Bob Newhart Show, we literally and figuratively meet clients where they are. Social workers often encounter men in health care, education, child welfare, and other settings. This gives social workers the opportunity to see and work with men in the settings where they live, work, and operate. Third, unlike many other helping professions, social work adheres to a person-in-environment model that emphasizes the biological, psychological, social, and spiritual factors that influence individual behaviors. As such, both social work researchers and practitioners are uniquely positioned to understand how dominant cultural scripts, like those around masculinity, can affect men in a myriad of ways and the systematic effects that this may have, in turn.

Social work researchers and practitioners should also address men's issues because of our professional ethics and values. Our work can provide practitioners with the insights they need to effectively work with male clients. In particular, we know little about how social and community interventions, practice models, and therapeutic techniques work with men, as a group, and among subgroups of men, fathers, and boys. In many cases, particularly in child and family services, social workers try to fit men into treatment modalities that are better designed for women and do little to draw on the strengths that men possess (Wexler, 2009). For example, masculine norms can be a significant source of strength for men who are trying to overcome addictions or make substantial changes in their lives (Courtenay, 2011). As such, our research can identify problem areas and solutions in ways that other disciplines cannot.

In conclusion, we hope that this special issue of Social Work Research reflects some of the issues facing research on men's issues. As you will notice, the vast majority of our articles consider issues pertaining to fatherhood, whereas very few address other issues with men-such as their physical health, mental health, or well-being. Thus, this issue helps identify strengths in social work research focused on men and fathers, while also identifying key weaknesses. As such, we hope that more discussion around men's issues and the impact of men and fathers on families and communities and research on men and fathers is started from the excellent scholarship that follows. SWR

\section{REFERENCES}

Addis, M. E. (2008). Gender and depression in men. Clinical Psychology: Science and Practice, 15(3), 153-168.

Addis, M. E., \& Mahalik, J. R. (2003). Men, masculinity, and the contexts of help seeking. American Psychologist, $58(1), 5-14$.

Afifi, M. (2007). Gender differences in mental health. Singapore Medical Journal, 48, 385-391.

Baum, N. (2016). The unheard gender: The neglect of men as social work clients. British Journal of Social Work, 46, 1463-1471.

Bellamy, J. L. (2009). A national study of male involvement among families in contact with the child welfare system. Child Maltreatment, 14(3), 255-262.

Coley, R. L., \& Coltrane, S. (2007). Commentary: Impact of father involvement on children's developmental trajectories: New findings panel for the National Fatherhood Forum. Applied Developmental Science, 11, 226-228.

Courtenay, W. H. (2011). Dying to be men. New York: Routledge.

Furman, R. (2013). Social work practice with men at risk. New York: Columbia University Press.

Holmes, E. K., Baumgartner, J., Marks, L. D., Palkovitz, R., \& Nesteruk, O. (2010). Contemporary contradictions and challenges facing married fathers and mothers. In K. S. Pearlman (Ed.), Marriage: Roles, stability, and conflict (pp. 157-171). Hauppauge, NY: Nova Science Publishers.

Jewkes, R., Flood, M., \& Lang, J. (2015). From work with men and boys to changes of social norms and reduction of inequities in gender relations: A conceptual shift in prevention of violence against women and girls. Lancet, 385(9977), 1580-1589.

National Institute of Mental Health. (2005). Real men, real depression. Bethesda, MD: National Institutes of Health.

Oksuzyan, A., Juel, K., Vaupel, J. W., \& Christensen, K. (2008). Men: Good health and high mortality: Sex differences in health and aging. Aging Clinical and Experimental Research, 20(2), 91-102.

Rochlen, A. B., Paterniti, D. A., Epstein, R. M., Duberstein, P. R., Willeford, L. C., \& Kravitz, R. L. (2010). Barriers in diagnosing and treating men with depression: A focus group report. American Journal of Men's Health, 4(2), 167-175.

U.S. Department of Labor, Bureau of Labor Statistics. (2016). Labor Force statistics from the current population survey. Retrieved from http://www.bls.gov/cps/ cpsaat11.htm

Wexler, D. B. (2009). Men in therapy: New approaches for effective treatment. New York: W. W. Norton.

World Health Organization. (2007). Gender disparities in mental health. New York: United Nations. 
Kevin Shafer, PhD, is assistant professor, School of Social Work, Brigham Young University, 2173 Joseph F. Smith Building, Provo, UT 84602; e-mail: kshafer@byu.edu. Jennifer L. Bellamy, PhD, is associate professor, Graduate School of Social Work, University of Denver.

Advance Access Publication October 19, 2016

\section{RESEARCH NOTES}

he Research Notes column presents
concise reports on the results of a study, discussions of methodological issues, solutions to problems, and development of ideas or insights. Send your manuscript as a Word document through the online portal at http:// swr.msubmit.net (initial, one-time registration is required).

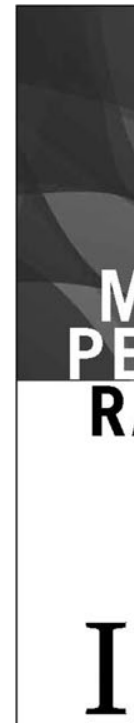

MULTICULTURAL PERSPECTIVES ON RACE, ETHNICITY, AND IIDENTITY

Elizabeth Pathy Salett and

Diane R. Koslow, Editors

T $\mathrm{n}$ the past 30 years, the United States has undergone an unprecedented and accelerated growth in the diversity of its population. These changes affect all elements of our society, underscoring the need for an informed and knowledgeable public that can understand, respect, and communicate with people of diverse backgrounds. Multicultural Perspectives on Race, Ethnicity, and Identity discusses the relationship between race, ethnicity, sense of self, and the development of individual and group identity. It further explores the question of who we are and who we are becoming from the perspective of our multicultural, multilingual, and globally interconnected world. This book offers readers the opportunity to examine the importance of ecological and environmental factors in defining how we experience our lives and the world around us.

The authors introduce and review numerous frameworks and models for understanding racial and ethnic identity development. Each chapter examines social, economic, and political processes related to building and preserving racial and ethnic identities and perceptions of self. Multicultural Perspectives on Race, Ethnicity, and Identity is a great resource for all social workers.

ISBN: 978-0-87101-460-3. 2015. Item \#4603. 224 pages. \$42.99. 1-800-227-3590 • www.naswpress.org
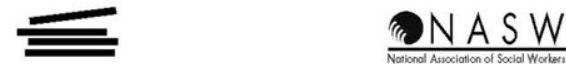

NASW PRESS 